\section{The patient's role in the decision-making process - a perspective from the Liverpool Ocular Oncology Centre}

RMJ Purbrick ${ }^{1}, \mathrm{KL} \mathrm{Tu}^{2}$ and BE Damato ${ }^{3}$
${ }^{1}$ Department of Neurosurgery, The Radcliffe Infirmary, Oxford, UK

${ }^{2}$ St Paul's Eye Unit, Liverpool, UK

${ }^{3}$ St Paul's Eye Unit, Liverpool, UK

Correspondence:

RMJ Purbrick,

Department of

Neurosurgery,

The Radcliffe Infirmary, Woodstock Road, Oxford OX2 6HE, UK Tel: + 447941946614 ; Fax: +44 1865224898 E-mail: robertpurbrick@ yahoo.co.uk

Received: 3 January 2005 Accepted: 25 July 2005

Published online:

2 September 2005

\begin{abstract}
Purpose To examine the patient's role in the decision-making process in a tertiary adult ocular oncology service.

Methods A prospective study was carried out of patients attending for follow-up at the Liverpool ocular oncology centre (LOOC), a tertiary adult ocular oncology service. Participants were patients who attended the clinic between September and October 2003. Through supervised completion of questionnaires, the main factors observed were: patients' preferred level of participation, patients' perceived level of participation, sources of information used by patients, and which sources they found most useful.

Results In all, 39 patients were included in the study. The majority of patients $(69.2 \%)$ would have preferred to make a shared decision with the doctor $(10.3 \%$ preferring an active role, $20.5 \%$ preferring a passive role), while $48.7 \%$ perceived having had a shared role $(25.6 \%$ felt they had had an active role, $25.6 \%$ a passive one). Outside the LOOC, general ophthalmologists were the most frequently cited source of information from health professionals, and were also scored as the most useful. Family and friends were the most common source of informal information, followed by use of the Internet. Tape recordings of the consultations were reported as the most popular resource provided by the LOOC.

Conclusions Patients attending the LOOC have a strong desire for involvement in the decision-making process. Patients receive little formal or informal information outside this tertiary centre. Further work is required to assess the effectiveness of physicians' communication skills and the
\end{abstract}

influence of their recommendations on patient choice.

Eye (2006) 20, 1034-1039. doi:10.1038/sj.eye.6702074; published online 2 September 2005

Keywords: access to information; patient views; ocular oncology

\section{Introduction}

The doctor-patient relationship has changed in recent years. It is no longer a paternalistic affair. Now the ideal is a partnership between patient and physician, where the available information is shared and decisions based on the patients' preferences, with members of the health-care team acting as advisors and interpreters. ${ }^{1}$

Patients' participation in medical decisionmaking is believed to have several potential benefits: decreased anxiety and depression, increased feelings of control over illness, enhanced sense of hope, increased self-efficacy, a better understanding of and commitment to their treatment, better compliance, and increased patient satisfaction with physicians. ${ }^{2-6}$

The Liverpool ocular oncology centre (LOOC) is a supraregional service specialising in adult ocular tumours. New patients are seen every Monday morning, with about half of these having melanoma. If treatment is required, patients are generally admitted on the same day for surgery on the following day so that, in most cases, discharge is possible before the end of the week. This set-up necessitates that decisions regarding treatment are made in a very short period of time.

Patients are given a wealth of information at the LOOC, including a tape recording of the consultation (routinely given to new patients 
since 1991), an information guide about the centre (since 2000), information leaflets about specific treatments, and where appropriate, copies of the letters to the GP are sent to the patient's home (since 2001). Patients have access to telephone and email helplines, and a clinical psychologist has been appointed. However, as the LOOC is a supraregional service, patients have normally been seen by an optician and general ophthalmologist and are likely to have received, or to have sought out, other information prior to their visit. This could influence the decision-making process. ${ }^{7}$

The aim of this study was to examine the patient's role in the decision-making process. The main factors observed were: patients' preferred level of participation, patients' perceived level of participation, sources of information used by patients, and which sources they found most useful.

\section{Materials and methods}

\section{Patients}

Patients were included in the study if they were attending a follow-up outpatient consultation at the LOOC. Patients were excluded if they had been referred after having had treatment at another tertiary centre.

Patients are first seen on Monday mornings at a dedicated new patient clinic. On arrival, they are seen by the receptionist, then the sift nurse, then the SpR or oncology fellow, before having the appropriate photography. They are then seen by the professor of ocular oncology, specialist nurse, and, after admission, by the anaesthetist. Most patients are operated on the day after being first seen at the LOOC.

\section{Study procedure}

The current prospective study was conducted at the LOOC between September 2003 and October 2003.

Ethical approval was not required for this audit.

Completion of the questionnaire was taken as consent to participate.

The questionnaire was adapted from two previous studies. ${ }^{8,9}$ It was produced after consultation with patients and staff and modified after being tested and commented on by eight patients.

Patients were asked to choose one from a list of five responses regarding their preferred role in the decisionmaking process. They were then asked to select the statement most accurately reflecting their perceived role from a similar list (see Results - Table 1). Responses were categorised as reflecting an active role, a shared role, or a passive role.

The second part of the questionnaire comprised questions about any information they had received outside the LOOC. Firstly, patients were asked whether they had received any information (written or spoken) from other health professionals, followed by information from other external sources. Patients were asked to state which two sources they had found most useful.

Information supplied by the LOOC was audited. Patients were asked to specify which items they had received, whether they or anyone else had used each one, the number of times they had used them, and to judge how useful they had found them (on a scale of 0-5).

Preferred and perceived levels of involvement in the decision-making process were compared and data concerning formal and informal sources of information assessed.

\section{Results}

A total of 39 patients were included in the study. Three patients declined an invitation to take part in the study, four patients were not included in analysis because of incomplete questionnaires, due to lack of patients' time as the questionnaires were completed during clinic, and two patients were excluded because they had been referred from another oncology centre. The study population consisted of 12 males and 27 females with an average age of 63 years (range 19-80). The length of time patients had been attending the LOOC ranged from 1 month to almost 10 years, with an average of 36 months.

Results for patients preferred and perceived roles are summarised in the table below.

All four patients who had stated a preference for an active role felt that this had been achieved. Of the 27 patients who preferred a shared role, five felt they

Table 1 Patients' preferred and perceived roles in the decision-making process

\begin{tabular}{|c|c|c|c|}
\hline & Category & Preferred & Perceived \\
\hline $\begin{array}{l}\ldots \text { to make the treatment decision on my own } \\
\ldots \text { to make the decision by myself after hearing the doctor's opinion }\end{array}$ & Active role & $4(10.3 \%)$ & $10(25.6 \%)$ \\
\hline$\ldots$ to make the decision together with the doctor & Shared role & $27(69.2 \%)$ & $19(48.7 \%)$ \\
\hline $\begin{array}{l}\ldots \text { doctor makes the decision after talking with me and hearing my opinion } \\
\ldots \text { doctor makes the decision on his or her own }\end{array}$ & Passive role & $8(20.5 \%)$ & $10(25.6 \%)$ \\
\hline
\end{tabular}




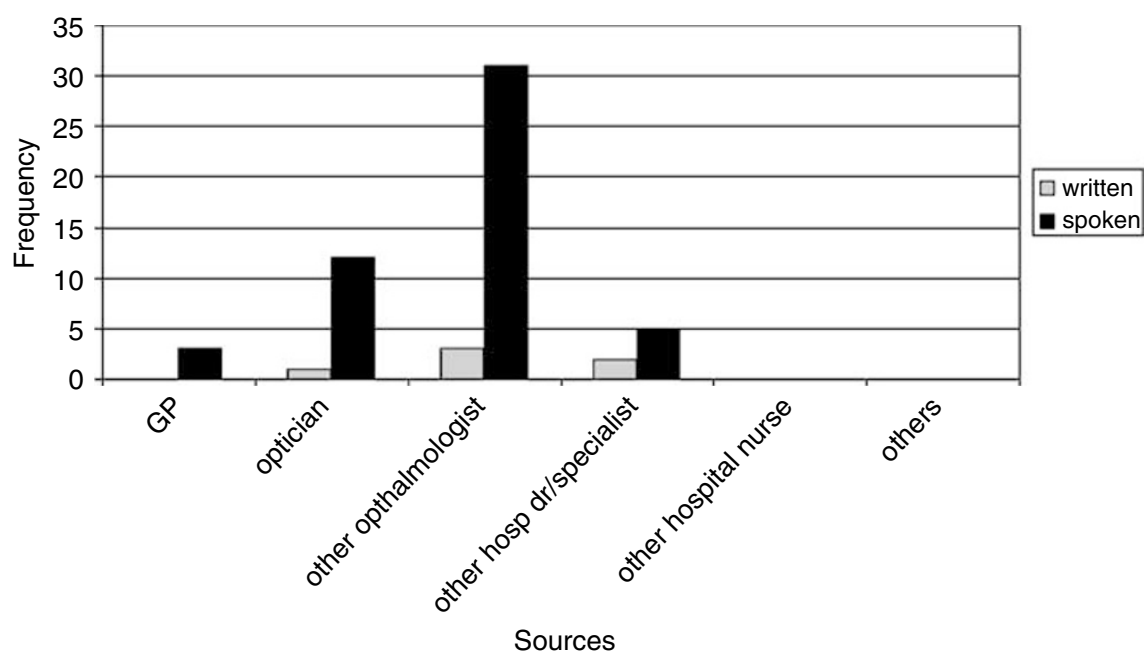

Figure 1 Health-care professionals reported by patients to have supplied specific verbal or written information.

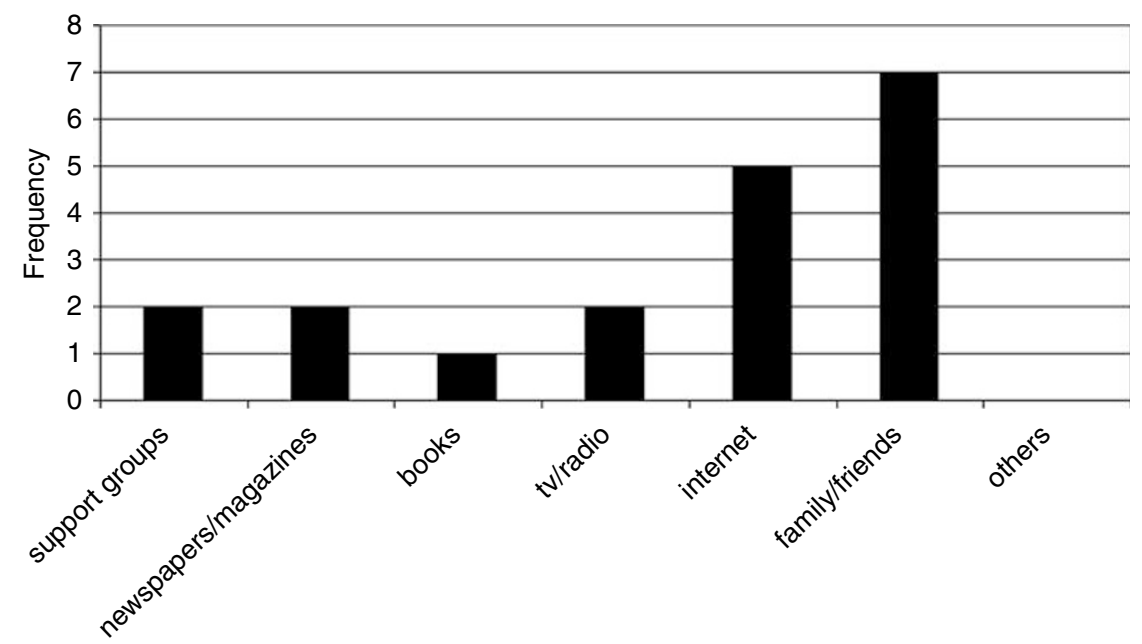

Figure 2 Informal sources of information used by patients.

had an active role and seven passive. One of the eight patients who preferred a passive role actually reported an active role, along with four shared and three passive.

Figure 1 shows the range of professionals, outside the LOOC, from whom patients had received either verbal or written information.

Informal sources were accessed less frequently (Figure 2).

Table 2 shows which sources patients had accessed outside the LOOC and which two sources they had found most useful. Two patients $(5.1 \%)$ did not receive any information from outside the LOOC, and so were unable to respond to this part of the questionnaire and 16 patients (41\%); only received information from one external source and, therefore, could not give a second choice.
Table 2 Sources of information ranked by patients as either 1st or 2nd most useful

\begin{tabular}{lcc}
\hline Source & Ranked 1st & Ranked 2nd \\
\hline Ophthalmologist & 24 & 5 \\
Optician & 3 & 7 \\
Family/friends & 3 & 3 \\
Other doctor or specialist & 3 & 1 \\
Internet & 3 & 1 \\
Media & 1 & 2 \\
Support groups & 0 & 2 \\
GP & 0 & 1 \\
\hline
\end{tabular}

Table 3 describes the written information received by patients from the LOOC, how they used it, and how useful it was to them. Patients were asked to rate how useful they had found each item on a scale from 0 to 5 , 
Table 3 Describing uptake, use and opinion of information provided by the LOOC

\begin{tabular}{|c|c|c|c|c|c|c|c|c|c|}
\hline \multirow[t]{2}{*}{ Source } & \multirow[t]{2}{*}{ Received? } & \multirow[t]{2}{*}{ Used? } & \multirow[t]{2}{*}{ Average \# of times used } & \multicolumn{6}{|c|}{ Rating } \\
\hline & & & & 0 & 1 & 2 & 3 & 4 & 5 \\
\hline Tape recording & $35(89.7 \%)$ & $28 / 35(80.0 \%)$ & 2.2 & 1 & 0 & 0 & 4 & 4 & 26 \\
\hline Blue book & $23(59.0 \%)$ & $21 / 23(91.3 \%)$ & 2.9 & 0 & 0 & 3 & 2 & 3 & 15 \\
\hline Information leaflets & $16(41.0 \%)$ & $15 / 16(93.8 \%)$ & 2.2 & 0 & 0 & 0 & 4 & 2 & 10 \\
\hline GP letters & $26(66.7 \%)$ & $26 / 26(100 \%)$ & 2.2 & 0 & 0 & 2 & 4 & 4 & 16 \\
\hline
\end{tabular}

with 0 being not useful at all and 5 being extremely useful.

\section{Discussion}

The majority of patients in the current study demonstrated a strong desire to be involved in making decisions regarding their treatment; $79.5 \%$ of patients preferred to play either an active or a shared decisionmaking role. This supports the current trend for actively involving patients in treatment decisions. ${ }^{10-14}$ These results are similar to those of a 1997 study by Degner et $a l_{1}^{15}$ investigating information needs and decisional preferences in women with breast cancer.

The level of involvement perceived by patients differed slightly from that preferred, but there was no definite swing towards either a more active or more passive role. However, seven of the eight patients who had stated a preference for a passive role felt that they had been more involved in treatment decisions, which could indicate the active inclusion of patients in the decision-making process. Indeed, it could be argued that, if patients were to act in a purely passive way, then it would be impossible to gain valid informed consent. Physician recommendations have been shown to potentially lessen patient autonomy, but investigation of this was beyond the scope of this project. ${ }^{16}$

Seven of the 27 patients preferring a shared role said that they had a passive role. Perhaps, in these patients the choice of treatment was so clear cut that there was little scope for decision-making; for example, if there was no choice but enucleation, or if the tumour was eminently suitable for a ruthenium plaque, then further discussion would have been superfluous. Due to the limitations of the NHS, a second opinion from a consultant at another oncology centre is not easily accessible.

It was noted during the interviews that particular care had to be taken when explaining the questions regarding a patient's preferred and perceived role in the decisionmaking process. When asked about their preferred role, a number of patients initially stated the role they felt they had played in treatment decisions. In addition, patients generally had to rely on their memory of the decisions that had to be made and, with an average time of 36 months since their first appointment, this is likely to have an effect on the accuracy of the results. Following a sample of patients from the initial consultation at the LOOC through to a follow-up appointment after treatment could eliminate these two possible sources of bias.

Tools, such as the OPTION scale, ${ }^{17}$ have been developed to measure the extent to which a clinician actively involves patients in treatment decisions. The required resources were not available at the time of this study, but this is an area in which further research could be carried out. It would then be possible to compare patients' perceptions of their role in the treatment decisions with the communication skills adopted. The Control Preferences Scale ${ }^{18}$ could also be used to more formally assess the degree of control an individual wants to assume when decisions are being made about medical treatment'.

The majority of patients had not accessed information from other sources. The most common source of information outside the LOOC was verbal information from another ophthalmologist. However, despite the fact that the vast majority of patients attending the LOOC are referred from a general ophthalmologist, over $20 \%$ of patients said that they had received no information at all from another ophthalmologist. This may indicate an understandable desire on the part of the referring ophthalmologist not to prejudge the consultation at the LOOC. The referring ophthalmologist was chosen as the most useful external source of information by $61.5 \%$ of patients, emphasising their importance in educating patients prior to referral.

General practitioners were cited as a source of verbal information by just three patients (7.7\%). A 'Red book' containing information for medical professionals is currently in production and the LOOC website (www.looc.org.uk) has a Guide and Information for Doctors section, which could, if properly publicised, help towards fulfilling a need with regard to GP education.

The patients reported little use of informal sources of information. Many commented that they found it difficult to access information about eye tumours elsewhere. These findings reinforce the importance of 
health-care professionals as information providers and educators.

In all, $89.7 \%$ of patients said they had received a tape recording of the consultation. This resource gained a high level of patient satisfaction, with $74.3 \%$ giving it the highest possible rating. The majority of patients stated that the tape, which has been in use since 1991, had aided their recall of the consultation, which is supported by a systematic review carried out by Scott et $a l^{19}$ in 2001. Patients also described using the tape as a method of informing members of their family about their condition. A study by Ah-Fat et $a l^{20}$ carried out in 1998 at the LOOC showed similar results and examines this subject in more detail.

The 'blue book', The Liverpool Ocular Oncology Centre: A Guide for Patients, was produced in 2001, from which time patients have been sent this book with their first appointment. In all, 59\% of patients reported that they had received this book, with $65.2 \%$ of them rating it as extremely useful. Two patients $(8.7 \%)$ said they had been shocked by the word 'Oncology' on the front cover, because they received this book with their first appointment at the LOOC and had not been told by the referring ophthalmologists what the centre was for or that they might have cancer.

In total, 16 patients $(41.0 \%)$ had received information leaflets. These are specific to certain treatments such as proton beam radiotherapy and ruthenium plaque radiotherapy, so it would not be expected that all patients would be given one of these. Again, the majority of patients were very satisfied with this information source, with 10 of the 16 patients $(62.5 \%)$ scoring the leaflets as five out of five.

In all, 26 patients $(66.7 \%)$ reported receiving copies of the letters sent from the LOOC to their GPs. Of these, 16 patients $(61.5 \%)$ rated the letters as extremely useful. Two patients $(7.7 \%)$ gave the GP letter negative marks, both stating that they found the language too complicated, and one patient suggested that a 'translation' of the letter into lay terms would be useful. The prospect of providing an alternative letter for patients was discussed with the team, but it was felt that this would undermine communication between the LOOC and general practitioners. ${ }^{21,22}$ A 2004 study by Krishna and Damato ${ }^{23}$ examines this subject in depth.

Patients attending the LOOC appear to have a strong desire for involvement in making decisions regarding their treatment. In order to participate fully in these decisions, patients need access to the relevant information. Patients are more than satisfied with the information provided by the LOOC, but receive little formal or informal information prior to their visit. Further work could be carried out to investigate which particular aspects of information patients value most highly, the effectiveness of communication skills being used, and the influence of physician recommendations on treatment decisions.

\section{References}

1 Say RE, Thompson R. The importance of patient preferences in treatment decisions - challenges for doctors. BMJ 2003; 327: $542-545$.

2 Orsino A. Medical decision-making and information needs in end-stage renal disease patients. General Hospital Psychiatry 2003; 25: 324-331.

3 Charles C, Gafni A, Whelan T. Decision-making in the physician-patient encounter: revisiting the shared treatment decision-making model. Social Sci Med 1999; 49: 651-661.

4 Lelie A. Decision-making in nephrology: shared decision making? Patient Educ Counsel 2000; 39: 81-89.

5 Sainio C, Lauri S, Eriksson E. Cancer patients' view and experiences of participation in care and decision making. Nurs Ethics 2001; 8: 97-112.

6 Charles CA, Whelan T, Gafni A, Willan A, Farrell S. Shared treatment decision making: what does it mean to physicians? J Clin Oncol 2003; 21: 932-936.

7 Coulter A, Entwistle V, Gilbert D. Sharing decisions with patients: is the information good enough? BMJ 1999; 318: 318-322.

8 Bruera E, Willey JS, Palmer JL, Rosales M. Treatment decisions for breast carcinoma: patient preferences and physician perceptions. Cancer 2002; 94: 2076-2080.

9 Rahi JS, Manaras I, Barr K. Information sources and their use by parents of children with ophthalmic disorders. Invest Ophthalmol Visual Sci 2003; 44: 2457-2460.

10 Montgomery AA, Fahey T. How do patients' treatment preferences compare with those of clinicians? Qual Health Care 2001; 10(Suppl): i39-i43.

11 Deber RB. Physicians in health care management: 8. The patient-physician partnership: decision making, problem solving and the desire to participate. Canad Med Assoc J 1994; 151: 423-427.

12 Strull WM, Lo B, Charles G. Do patients want to participate in medical decision making? JAMA 1984; 252: 2990-2994.

13 Parascandola M, Hawkins J, Danis M. Patient autonomy and the challenge of clinical uncertainty. Kennedy Inst Ethics J 2002; 12: 245-264.

14 Whitney SN. A new model of medical decisions: exploring the limits of shared decision making. Med Decis Making 2003; 23: 275-280.

15 Degner LF, Kristjanson LJ, Bowman D, Sloan JA, Carriere KC, $\mathrm{O}^{\prime}$ Neil $\mathrm{J}$ et al. Information needs and decisional preferences in women with breast cancer. JAMA 1997; 277: 1485-1492.

16 Gurmankin AD, Baron J, Hershley JC, Ubel PA. The role of physicians' recommendations in medical treatment decisions. Med Decis Making 2002; 22: 262-271.

17 Elwyn G, Edwards A, Wensing M, Hood K, Atwell C, Grol R. Shared decision making: developing the OPTION scale for measuring patient involvement. Qual Saf Health Care 2003; 12: 93-99.

18 Degner LF, Sloan JA, Venkatesh P. The Control Preferences Scale. Canad J Nurs Res 1997; 29: 21-43.

19 Scott JT, Entwistle VA, Sowden AJ, Watt I. Giving tape recordings or written summaries of consultations to people with cancer: a systematic review. Health Expect 2001; 4: 162-169. 
20 Ah-Fat FG, Sharma MC, Damato BE. Taping outpatient consultations: a survey of attitudes and responses of adult patients with ocular malignancy. Eye 1998; 12: 789-791.

21 Elwyn G, Edwards A, Gwyn R, Grol R. Towards a feasible model for shared decision making: focus group study with general practice registrars. BMJ 1999; 319: 753-756.
22 Coulter A, Peto V, Doll H. Patients' preferences and general practitioners' decisions in the treatment of menstrual disorders. Fam Pract 1994; 11: 67-74.

23 Krishna Y, Damato BE. Patient attitudes to receiving copies of outpatient clinic letters from the ocular oncologist to the referring ophthalmologist and GP. Eye (advance online publication, 15 October 2004). 